\title{
Fermentation of Tender Coconut Water by Probiotic Bacteria Bacillus coagulans
}

\author{
Aishwarya Singh Gangwar ${ }^{\mathrm{a}}$, Aastha Bhardwaj ${ }^{\mathrm{a}}$, And Vasudha Sharma ${ }^{\mathrm{a}^{*}}$ \\ ${ }^{\text {a }}$ Department of Food Technology, Jamia Hamdard (Deemed to be University), New Delhi - 110062, India \\ ${ }^{*}$ Corresponding author \\ vasudhakatwal@gmail.com \\ TEL: $+91-9810288903$
}

Received: 20 July 2017; Published online: 18 April 2018

\begin{abstract}
Coconut water is currently being considered as an elixir for patients suffering from diseases like dengue and malaria as well as chikungunia to provide hydration properties to the body. It has become a popular beverage for many people owing to its palatability and high mineral content. In this study, the growth, survival and fermentation performance of the probiotic bacterium Bacillus coagulans in coconut water was assessed in order to produce a novel non-dairy, probiotic beverage. The species was characterized on the basis of morphology, physiology and biochemical parameters and its probiotic attributes were assessed. Batch fermentations were carried out for 2 days at a constant $37^{\circ} \mathrm{C}$, thereafter the samples were subjected to microbiological and chemical analysis. The results suggested that the specie produced lactic acid and was acid and bile tolerant. The $\mathrm{pH}$ and titratable acidity of probiotic fermented coconut water were found to be 4.4 and $0.53 \%$ lactic acid, respectively. The viscosity of fermented coconut water increased significantly from an initial $5.13 \mathrm{mPa} . \mathrm{s}$ to $5.35 \mathrm{mPa}$.s because of the increase in soluble solids content due to exopolysaccharide production by $B$. coagulans during fermentation. Also, the overall acceptability score of probiotic coconut water was higher than tender coconut water, suggesting its feasibility for use as a probiotic beverage.
\end{abstract}

Keywords: Probiotic non dairy beverage; Fermented coconut water; Sensory evaluation; Physicochemical characteristics

\section{Introduction}

According to the World Health Organization and the Food and Agriculture Organization of the United Nations (FAO / WHO, 2001), probiotics are defined as "live microorganisms which, when administered in adequate amounts, confer a health benefit on the host". Numerous studies have highlighted the health benefits associated with consumption of probiotic bacteria. In the past decade, there has been an increase in consumer demand for functional foods such as yoghurt and other fermented dairy products supplemented with probiotic organisms (Penna,
Rao-Gurram, \& Barbosa-Canovas, 2007). However, dairy substrates may contain potential allergens, such as casein and they require cold storage to enhance their shelf life. Also, the cholesterol content of dairy products is high. Owing to such facts and the increasing trend of vegetarianism, the demand for novel products with non-dairy matrices has expanded (Ranadheera, Baines, \& Adams, 2010). Also producing probiotic products with foods and beverages which are part of day-to-day life is encouraged. This has led to an increased demand for non-dairy probiotic foods, such as coconut aqueous extract, fruit drinks, nutrition bars, soy products and cereal- 
based products. The nutritive values and wide distribution of these raw materials are important when they are used as functional food items (Angelov, Gotcheva, Kuncheva, \& Hristozova, 2006). Tender coconut water (TCW), the liquid endosperm obtained from immature green coconuts, in its natural form is a refreshing and nutritious beverage, widely consumed around the world due to its beneficial health properties (Pummer, Heil, Maleck, \& Petroianu, 2001). Moreover, coconut water plays an important alternative role for oral rehydration and even for intravenous hydration of patients in remote regions (Campbell-Falck, Thomas, Falck, Tutuo, \& Clem, 2000) in addition to providing protection against induction of myocardial infarction (Anurag \& Rajamohan, 2003). It was identified in the late 1930s as a nutrient helping to reduce anemia in pregnancy (Jackson, Gordon, Wizzard, McCook, \& Rolle, 2004) and which also helped to prevent mitochondrial toxicity induced by methanol metabolites. The major chemical constituents of coconut water are sugars and minerals and minor ones are fat and nitrogenous substances.

Interestingly, the perception and utilization of coconut water has evolved over the years owing to its unique chemical composition of sugars, vitamins, minerals, amino acids, enzymes and phytohormones that play different functional roles in the human system (Yong, Ge, Ng, \& Tan, 2009). One example is the consumption of coconut water as a refreshing and hydrating beverage due to its rich mineral content of sodium, potassium, magnesium and calcium, which can replenish the electrolytes of the human body excreted through perspiration (Saat, Singh, Sirisinghe, \& Nawawi, 2002). Studies have shown that coconut water has hydrating and exercise performance effects that are comparable to those of carbohydrate electrolyte sports drinks (Kalman, Feldman, Krieger, \& Bloomer, 2012). Chauhan, Archana, Singh, Raju, and Bawa (2014) blended coconut water with lemon juice to develop a refreshing beverage by optimizing the $\mathrm{pH}$, colour and sensory attributes (appearance, aroma, taste, consistency and overall acceptability).

Current knowledge on the fermentation of coconut water is rather limited (Kuswardani,
Kusumawati, Srianta, \& Sabrina, 2011), especially fermentation with probiotic bacteria. However, Dharmasena (2012) recently developed a novel non-dairy probiotic beverage with a mixture of oat meal and coconut water using probiotic Lactobacillus plantarum Lp 115- 400B. Although lactic acid bacteria (LAB) are the most commonly used probiotics, some spore-forming bacteria have also been exploited as probiotics due to their unique properties. Lee, Boo, and Liu (2013) studied the fermentation performance, growth patterns and survival of Lactobacillus acidophilus and Lactobacillus casei in coconut water. Prado et al. (2015) developed a non dairy fermented functional beverage using coconut water for its hydrating properties, functional health properties and nutritional benefits.

The genus Bacillus is the most extensively studied group of spore-forming probiotics. Other spore-formers being used as probiotic bacteria are Paeni Bacillus polymyxa and Brevi Bacillus laterosporus that were initially classified as Bacillus species (Cutting, 2011). There are several advantages of using spores over other nonspore forming bacteria. Spores are heat resistant and can survive harsh conditions during production and storage processes. They are also able to withstand the extreme physiological conditions such as the low $\mathrm{pH}$ of the gastrointestinal tract, bile salts and enzymes (Cutting, 2011). Bacillus coagulans, a widely used probiotic, has been shown to induce antibody production in humans. This probiotic bacterium is the most commercially available and investigated probiotic bacterium, with proven beneficial impacts on health in animal and human trials (Hawrelak, 2003).

In order to be able to exert its beneficial effects, a successful potential probiotic strain is expected to have a number of desirable properties. Bacterial characterization with good probiotic properties is of great importance in probiotic functional foods. In addition to production of lactic acid, the acid and bile tolerance are two fundamental properties that indicate the ability of probiotic microorganism to survive the passage through the upper gastrointestinal tract, particularly the acidic conditions in the stomach and the presence of bile in the small intestine (Hyronimus, Le Marrec, Sassi, \& Deschamps, 2000).

The objective of the present investigation was to

IJFS | April 2018 | Volume $7 \mid$ pages 100-110 
assess the growth, survival and fermentation performance of probiotic bacterium B. coagulans in coconut water to produce a novel non-dairy probiotic beverage, which could provide both hydration as well as probiotic benefits to all individuals, especially athletes and recreationally active fitness enthusiasts.

\section{Materials and Methods}

\subsection{Procurement and preparation of raw material}

Tender coconuts of the Cocus nucifera type, age 5-7 weeks, were chosen for this study. These were purchased from a local market in Delhi. Tender coconut water was collected in a sterile beaker (500 ml capacity) under aseptic precautions as per method given by Acharya, Gupta, Golwala, Store, and Sheth (1965). The flask was plugged with cotton and autoclaved at $121^{\circ} \mathrm{C}$ at $15 \mathrm{psi}$ for 15 minutes. The flask with sterile coconut water was cooled and stored at $4^{\circ} \mathrm{C}$ prior to the fermentation stage.

\subsection{Chemicals}

Sodium hydroxide, sodium chloride, hydrochloric acid, bile salts, L-cysteine, dextrose, peptone, yeast extract, beef extract, MRS agar, MRS broth, GYE broth and agar were obtained from Sigma-Aldrich (New Delhi, India). , Gallic acid, phenol, 3, 5-dinitro salicylic acid (DNS) reagent, sulphuric acid, methanol, ethanol, hexane, ether, crystal violet, Rochell's salt, bovine serum albumin (BSA) and sodium sulphite were procured from HiMedia (Mumbai, India). All chemicals employed were of reagent grade.

\subsection{Procurement of Probiotic culture and Preparation of Bacterial Suspension Culture}

B. coagulans MTCC 5856 strain used in the study was procured from Microbial Type Culture Centre and Gene Bank (MTCC) at the Institute of Microbial Technology (IMTECH), Chandigarh, India. The spores of B. coagulans were propagated separately in sterile MRS broth in a sterile Erlenmeyer flask for up to $48 \mathrm{~h}$ at $37^{\circ} \mathrm{C}$ aerobically and then stored at $4^{\circ} \mathrm{C}$ until use.

\subsection{Analysis of Probiotic attributes}

The probiotic attributes of the species such as the ability to produce lactic acid, high acid tolerance and their ability to deconjugate bile salts were investigated (Aly, Abd-El-Rahman, John, \& Mohamed, 2008).

\section{Analysis of Probiotic attributes}

To determine the tolerance of the specie to low pH, the method of Pennacchia et al. (2004) was used with slight modifications. For this purpose, active cultures were used (incubated for 16-18 h). A $0.5 \mathrm{ml}$ aliquot of the bacterial culture was inoculated in $10 \mathrm{ml}$ of phosphate buffered saline adjusted to $\mathrm{pH} 2.5$ with $4 \mathrm{~N} \mathrm{HCl}$. Cultures were incubated at $37^{\circ} \mathrm{C}$. During $0,1,2$ and $3 \mathrm{~h}$ of incubation, viable microorganisms were enumerated using the pour plate technique on MRS agar plate at $37^{\circ} \mathrm{C}$.

\section{Bile salt tolerance}

The tolerance capacity of $B$. coagulans for high bile concentration was checked using the method suggested by Chung, Kim, Chun, and Ji (1999). A $1 \%$ concentration of bile salts in sterile distilled water was inoculated with $1 \%$ active bacterial suspension and incubated at $37^{\circ} \mathrm{C}$. After incubation for $4 \mathrm{~h}$, viable colonies were enumerated each hour using pour plate technique.

\section{Production of lactic acid}

The qualitative test for lactic acid production by $B$. coagulans was carried out using the method as described by Demirci, Pometto, and Johnson (1993). Glucose yeast agar plates were prepared and dilutions were made from the main culture suspension. $1 \mathrm{ml}$ of the bacterial suspension was pour plated from the final dilution tube. After solidification, the plates were incubated at $37^{\circ} \mathrm{C}$ for 48 hours. The colonies thus obtained 
were transferred aseptically to $15 \mathrm{ml}$ of previously sterilized and cooled glucose yeast extract liquid broth. This was incubated at $37^{\circ} \mathrm{C}$ for 48 hours and was then centrifuged at 2500-3000 rpm for 10 minutes. The clear supernatant was transferred to a separating funnel and extracted by using $5 \mathrm{ml}$ of dilute sulphuric acid (10\%) and $50 \mathrm{ml}$ of ether. The ether layer was then collected, evaporated in water bath and the residue thus obtained was dissolved in $5 \mathrm{ml}$ of water. To this, Uffelman's reagent (prepared by adding two drops of $1 \mathrm{~N}$ ferric chloride to $10 \mathrm{ml}$ of $1 \%$ phenol solution) was added dropwise and the colour change was observed.

\subsection{Preparation of the inoculum}

For preparation of the inoculum, $25 \mathrm{ml}$ of sterile tender coconut water was inoculated aseptically with $1 \% \mathrm{v} / \mathrm{v} \mathrm{ml}$ of bacterial suspension culture and incubated at $37^{\circ} \mathrm{C}$ for $12-14 \mathrm{~h}$. This was then serially diluted to obtain a working culture containing $10^{8} \mathrm{CFU} / \mathrm{ml}$. $1 \mathrm{ml}$ from the respective tube was pour plated onto the MRS agar media plate and the plate was incubated at $37^{\circ} \mathrm{C}$ for $48 \mathrm{~h}$. The number of colonies between 30 300 were considered ideal during counting. The viable spore count was obtained by the following formula:

The viable spore count $=$ Number of colonies per plate $\times$ Final dilution factor

\subsection{Fermentation of the Tender Coconut Water}

Fermentations with $B$. coagulans were carried out in $150 \mathrm{ml}$ of sterile coconut water in sterile $250 \mathrm{ml}$ Erlenmeyer flasks. These flasks containing sterile coconut water were inoculated with 1 $\%(\mathrm{v} / \mathrm{v})$ pre-culture of the probiotic strain from the respective broth. The batch fermentations were carried out for 2 days at a constant $37^{\circ} \mathrm{C}$ in triplicate. After two days, the samples were taken aseptically after swirling the conical flasks gently for homogenization and these were subjected to microbiological and chemical analysis.

\subsection{Analytical determination}

Samples $(20 \mathrm{ml})$ were taken after 2 days of fermentation, and the viability of the probiotic culture, $\mathrm{pH}$, total soluble solids $\left({ }^{\circ} \mathrm{Brix}\right)$, acidity and cell biomass of the probiotic coconut water were determined. Similar tests were also carried out for the tender coconut water sample. The $\mathrm{pH}$ of tender coconut water and fermented coconut water was measured using a digital $\mathrm{pH}$ meter (TOSHCON, India) at $25{ }^{\circ} \mathrm{C}$. The total soluble solids were determined using an Abbe refractometer (AC0012, MRC Scientific Instruments. India) and the total soluble solid content was expressed as ${ }^{\circ}$ Brix and Refractive Index at $25^{\circ} \mathrm{C}$. The rheological measurements were carried out at $25^{\circ} \mathrm{C}$ using a controlled stress viscometer (Brookfield VIS-S2, MRC Scientific Instruments, India) equipped with a coaxial cylinder (cylinder no. 4); the radii ratio of coaxial cylinder was 1.08477. The acidity was determined by titration with standard $0.01 \mathrm{M} \mathrm{NaOH}$ solution, using phenolphthalein as indicator and acidity was expressed as \% citric acid (Ranganna, 1986). The biomass/cell density was determined spectrophotometrically at $540 \mathrm{~nm}$ using the MacFarland scale (Kandler \& Weiss, 1986), both pre and post the prebiotic fermentation.

\section{Estimation of total sugars and reducing sugars}

Total sugars of tender coconut water and fermented coconut water were determined colorimetrically using the phenol-sulphuric acid method and expressed as percentage sugar (Miller, 1959). The absorbance was measured at $490 \mathrm{~nm}$ and expressed as glucose concentration $(\mathrm{mg} / \mathrm{ml})$. Similarly, the reducing sugars of tender coconut water and fermented coconut water were determined colorimetrically using 3 , 5-dinitro salicylic acid (DNS) reagent and expressed as \% (Miller, 1959). The absorbance was measured at $540 \mathrm{~nm}$ and expressed as glucose concentration $(\mathrm{mg} / \mathrm{ml})$.

\subsection{Viable cell determination}

Appropriate dilutions from coconut water samples were made using sterile peptone water (1 
$\mathrm{gl}^{-1}$ ) and pour plated onto MRS agar. Plates were then incubated at $37^{\circ} \mathrm{C}$ for $48 \mathrm{~h}$. The experiment was performed in triplicate and the average number of colony-forming units per millilitre $(\mathrm{CFU} / \mathrm{ml})$ were determined using a Darkfield Quebec Colony Counter.

\subsection{Sensory evaluation of Fermented Coconut water}

Sensory quality of the fermented coconut water was measured after 7 days of fermentation using a 9 point hedonic scale, with respect to the appearance/colour, smell/odour, aroma/flavour, taste and texture/mouthfeel, and for assessment of overall acceptability of the product. Sensory evaluation was carried out by a semi trained panel consisting of 30 food scientists and technologists (between 20-45 years of age) chosen from faculty members and post graduate food technology students of the department. The samples were presented at $20{ }^{\circ} \mathrm{C}$ in the sensory evaluation laboratory. The samples were coded and presented individually to each panellist to avoid bias. Potable water to rinse between the two samples was also supplied. The panellists were asked to record their observations on the sensory sheet using the scales described above.

The research was approved by the institutional human experimentation committee or equivalent, and informed consent was obtained from the participants.

\subsection{Statistical analysis}

Results were expressed as mean values \pm standard deviation of at least three replications. Results were statistically evaluated by ANOVA (Minitab 14) at a confidence level of 0.95 .

\section{Results and Discussion}

\subsection{Analysis of probiotic attributes}

\section{Resistance to low pH}

Strains need to be resistant to the stressful conditions of the stomach ( $\mathrm{pH}$ 1.5-3.0) so resistance to $\mathrm{pH} 3$ is often used in in vitro assays to determine the resistance of probiotic species to stomach pH. Food usually stays in the stomach for about $3 \mathrm{~h}$ so this time limit was taken into account in the research (Prasad, Gill, Smart, \& Gopal, 1998) Since a significant decrease in the viability of strains is often observed at $\mathrm{pH} 2.0$ and below, phosphate buffered saline (PBS) was used with the $\mathrm{pH}$ adjusted to 3.0 to select strains resistant to low $\mathrm{pH}$. Effects of low $\mathrm{pH}$ (at 2.5) and survivability of $B$. coagulans at $0,1,2$ and $3 \mathrm{~h}$ intervals are shown in Table 1 . No effect of low $\mathrm{pH}$ (at 2.5) on B. coagulans was observed, suggesting that the colonies were able to survive the low $\mathrm{pH}$ conditions and were tolerant to high acid. This agreed with results reported by Argyri et al. (2013) where nine strains of Lactobacillus showed very high resistance to low $\mathrm{pH}$ (L. plantarum, $L$. pentosus, L. casei subsp paracasei). Acid tolerance can be mediated by membrane ATPases as described for L. acidophilus by Lorca and de Valdez (2001).

\section{Bile salts tolerance}

As the mean intestinal bile concentration is believed to be $0.3 \%(\mathrm{w} / \mathrm{v})$ and the residence time of food in small intestine is estimated to be $4 \mathrm{~h}$ (Prasad et al., 1998), this parameter was considered. Bile salts tolerance of $B$. coagulans at various time intervals are shown in Table 2 . The results showed that the specie retained viability with no reduction in the cell count at $1 \%$ bile salt concentration. B. coagulans showed a good tolerance towards bile salts. Similar results have been reported by Jensen, Grimmer, Naterstad, and Axelsson (2012) where Lactobacillus species were found to tolerate gastric juices with negligible reduction in the viability.

In high bile salts concentration, most bacteria show an inability to survive, but spore formers show a better tolerance. Bacillus sp. as probiotics, survive the transit very well since they are in the form of spores (Duc, Hong, Barbosa, Henriques, \& Cutting, 2004). Bile secreted in the small intestine reduces the survival of bacteria by destroying their cell membranes, whose major components are lipids and fatty acids and these modifications may affect not only the cell permeability and viability, but also the interac- 
Probiotic tender coconut water $\mid 105$

Table 1: Effect of low $\mathrm{pH}$ and bile salts on survivability of B. coagulans

\begin{tabular}{ccc}
\hline $\mathbf{p H}$ & Time duration (h) & No. of viable colonies $(\log \mathbf{C F U} / \mathbf{m l})$ \\
\hline 2.5 & 0 & $9.74 \pm 0.44^{c}$ \\
2.5 & 1 & $9.71 \pm 0.31^{c}$ \\
2.5 & 2 & $9.55 \pm 0.05^{b}$ \\
2.5 & 3 & $9.08 \pm 0.57^{a}$ \\
\hline Bile salt concentration (\%) & Time duration (h) & No. of viable colonies $(\log \mathbf{C F U} / \mathbf{m l})$ \\
\hline 1 & 0 & $9.83 \pm 0.43^{d}$ \\
1 & 1 & $9.81 \pm 0.35^{c}$ \\
1 & 2 & $9.73 \pm 0.21^{b}$ \\
1 & 3 & $9.69 \pm 0.18^{a}$ \\
1 & 4 & $9.65 \pm 0.36^{a}$ \\
\hline
\end{tabular}

Means and standard deviation for $n=3$; Values within columns with different superscripts were significantly different $(\mathrm{p}<0.05)$ according to Duncan's multiple test range

tions between the membranes and the environment (Gilliland, Staley, \& Bush, 1984).

\section{Production of lactic acid}

$B$. coagulans showed positive results for lactic acid production capability. The solution turned bluish, violet to yellow which suggested the presence of lactic acid in the medium. This meant that the medium contained sugars that could be fermented by the bacterium to produce lactic acid.

\subsection{Analytical determination}

\section{pH and total soluble solids}

The $\mathrm{pH}$ of tender coconut water and probiotic fermented coconut water was found to be 5 and 4.4 respectively. Fermentation causes a rapid decrease in $\mathrm{pH}$ from 5.02 to 4.44 . B. coagulans could tolerate acid medium and survive during fermentation process. The total soluble solids in tender coconut water and probiotic fermented coconut water were found to be 5.0 and $6.0^{\circ} \mathrm{Brix}$ respectively, suggesting that the increase in viable cell count corresponded to the decrease in $\mathrm{pH}$ and sugars consumed during fermentation. Total soluble solids content was $5.0^{\circ}$ Brix which indicated that solids present in tender coconut water was mainly soluble solids such as sugars. An increase in total soluble solids content of the fermented probiotic coconut water was due to the increase in viable cell counts after fermentation. The refractive index was found to be 1.340 and 1.342 in tender coconut water and fermented coconut water, respectively. It showed the purity of the coconut water.

\section{Titratable acidity}

Titratable acidity in coconut water samples was found to be $0.18 \%$ (citric acid) and $0.53 \%$ (lactic acid) respectively. Tender coconut water showed a titratable acidity value of $0.18 \%$ (citric acid) due to the presence of ascorbic acid. After fermentation, the titratable acidity value was 0.53 $\%$ lactic acid. Lactic acid is the major end product of the conversion of carbohydrates due to utilization of sugars present in coconut water. $B$. coagulans is a typical strain reported for lactic acid production; the thermophilic character of this strain (growth at $52^{\circ} \mathrm{C}$ ) indicates that it is particularly adapted for industrial production of lactate without sterile conditions (Payot, Chemaly, \& Fick, 1999).

\section{Total sugars and reducing sugars}

Total sugars and reducing sugar in tender coconut water was $3.96 \%$ and $2.37 \%$ after fermentation, which decreased to $3.15 \%$ and $2.27 \%$ respectively due to utilization of sugars present 
$106 \mid$ Gangwar et al.

Table 2: Physico-chemical characteristics of tender coconut water (TWC) and fermented coconut water (FWC)

\begin{tabular}{clcc}
\hline S.No. & \multicolumn{1}{c}{ Parameter } & TCW & FCW \\
\hline 1. & $\mathrm{pH}$ & $5.02 \pm 0.03^{a}$ & $4.44 \pm 0.12^{b}$ \\
2. & Total soluble solids $\left({ }^{\circ}\right.$ Brix) - Refractive Index & $5.0-1.340(\mathrm{RI})^{a}$ & $6.0-1.342(\mathrm{RI})^{b}$ \\
3. & Viscosity (mPa.s) at $25{ }^{\circ} \mathrm{C}$ & $5.13 \pm 0.04^{a}$ & $5.35 \pm 0.02^{b}$ \\
4. & \% Titrable acidity & $0.18 \pm 0.01^{a}(\%$ Citric acid) & $0.53 \pm 0.02^{b}(\% \text { Lactic acid })^{a}$ \\
5. & Biomass/Cell density at $540 \mathrm{~nm}$ & $0.121 \pm 0.02^{a}$ & $0.583 \pm 0.01^{b}$ \\
6. & Total Sugars (\%) & $3.96 \pm 0.10^{a}$ & $2.37 \pm 0.07^{b}$ \\
7. & Reducing sugar (\%) & $3.15 \pm 0.05^{a}$ & $2.27 \pm 0.02^{b}$ \\
\hline
\end{tabular}

Means and standard deviation for $n=3$; Values within rows different superscripts were significantly different $(\mathrm{p}<0.05)$ according to a paired t-test

in tender coconut by the species during fermentation.

\section{Flow behaviour}

Rheological parameters are good indicators of texture and important for consumer acceptance. The viscosity values of tender coconut water and fermented coconut water was 5.13 and 5.35 $\mathrm{mPa} . \mathrm{s}$ at $25^{\circ} \mathrm{C}$ depending upon the concentration. Total soluble solids content had a significant effect on viscosity of tender coconut water. The magnitude of viscosity of fermented coconut water increased significantly $5.35 \mathrm{mPa} . \mathrm{s}$ with the increase in soluble solid content due to exopolysaccharide production by $B$. coagulans. Several strains of $B$. coagulans have been studied for their exopolysaccharide production. The probiotic bacterium produces an exopolysaccharide (EPS) during exponential and stationary growth phases (Kodali \& Sen, 2008).

Microbial exopolysaccharides are getting attention as natural thickeners. Most of the economically important bacterial EPS are produced by $\mathrm{LAB}$, which are manipulated as probiotics to improve rheology and texture of fermented products.

The viscosity of tender coconut water is strongly depended on inter-molecular forces between molecules and water-solute (sugars and acids) interactions, which result from the strength of hydrogen bonds and inter-molecular spacing as both were strongly dependent on concentration and temperature. An increase in soluble solid content leads to increase in hydrated molecules and hydrogen bonding with hydroxyl groups of solute, which would enhance the flow resistance that leads to increase in viscosity of liquid. In case of tender coconut water, soluble solids was mainly due to the sugars content and in case of fermented coconut water, viable cells and exopolysaccharide played an important role in the viscosity values.

\section{Biomass / Cell density}

The biomass / cell density was determined spectrophotometrically at $540 \mathrm{~nm}$. The optical densities of tender coconut water and fermented coconut water were 0.121 and 0.683 respectively. The cell density of fermented coconut water determined at $540 \mathrm{~nm}$ was 0.683 , which was higher than 0.600 that corresponded to $10^{9} \mathrm{CFU} / \mathrm{mL}$, using the Mac Farland scale. This is ideal for probiotic beverage functionality.

\section{Viable cell counts}

In order to obtain the potential health benefits, the population of probiotics in a product, the viability of probiotic microorganisms and their ability to activate at the desired site in the alimentary canal are very important. The initial inoculum size of probiotics in the selected food item is critical. The effective daily dose of probiotics is considered to be $10^{9}-10^{11} \mathrm{CFU}$ (Sanders, 1999). Hence, consumption of $100 \mathrm{ml}$ or a $\mathrm{g}$ of a product bearing the therapeutic minimum $\left(10^{6}\right.$ $10^{8} \mathrm{CFU} / \mathrm{ml}$ or $\mathrm{g}$ of the product), would satisfy the daily requirement. The viable cell counts for 
Table 3: Evaluation of sensory properties of coconut water after 7 days of fermentation. Attribute scales: $1-9$

\begin{tabular}{ccc}
\hline Attributes & Fermented Coconut Water & $\begin{array}{c}\text { Tender Coconut Water } \\
\text { (Control) }\end{array}$ \\
\hline Appearance / Colour & $7.5 \pm .04^{a}$ & $9 \pm .30^{b}$ \\
Smell / Odour & $7.5 \pm .12^{a}$ & $7.5 \pm .10^{a}$ \\
Taste & $7.5 \pm .04^{a}$ & $6 \pm .14^{b}$ \\
Mouthfeel & $7.5 \pm .08^{a}$ & $6 \pm .21^{b}$ \\
Overall acceptability & $7 \pm .12^{a}$ & $6 \pm .20^{b}$ \\
\hline
\end{tabular}

The experimental values within rows with different superscripts were significantly different $(\mathrm{p}<0.05)$ according to a paired $t$-test

fermented coconut water were found to $9.73 \mathrm{log}$ $\mathrm{CFU} / \mathrm{ml}$ (Table 1), showing that it could be used successfully as a vehicle for probiotics.

The physico-chemical characteristics of tender coconut water and fermented coconut water are summarized in Table 2.

\subsection{Sensory evaluation of Fermented Coconut water}

Sensory properties were chosen as the main criterion of the quality of fermented products, being the most important attribute for consumers.

According to the consensus of the panellists during sensory evaluation, the overall acceptability on a 9 point hedonic scale of fermented coconut water was found to be higher than tender coconut water. It was determined that the main descriptors that characterized the product were acidity and sweetness, with acidity being the attribute responsible for the sensory difference perceived by the panellists.

The parameter of fluid food quality related to rheological viscosity is known as mouthfeel and is defined as the mingled experience derived from the sensation on the skin of the mouth after ingestion of a food or beverage. Nevertheless, the fermented coconut water still had high concentrations of residual sugars, which would enable retention of sweetness. The evaluation parameters and their respective scores are shown in Table 3 .

\section{Conclusions}

In this study, tender coconut water was used as the sole fermentation medium, without any additives, to ensure that it was the only raw material that regulated the growth and metabolism of the probiotic bacteria. The good adaptation of $B$. coagulans in the tender coconut water showed that if a potential probiotic strain is used as a starter culture then it might produce a fermented product with defined and consistent characteristics and possibly health-promoting properties. Fermented coconut water gives the advantages of plant-based products, and the presence of live bacteria with probiotic qualities enhances the benefits. In conclusion, the present study demonstrated good growth of probiotic $B$. coagulans in tender coconut water. These results suggest the feasibility of fermenting coconut water into a probiotic beverage, especially for its nutrition, with the health benefits of probiotics.

\section{Acknowledgements}

The authors gratefully acknowledge Department of Food Technology, Jamia Hamdard, for support and development towards this project.

\section{References}

Acharya, V. N., Gupta, K. C., Golwala, A. F., Store, S. D., \& Sheth, U. K. (1965). Comparative study of intravenous use of natural coconut water. synthetic coconut water and glucose saline in acute gastro-enteritis. In- 
dian Journal Of Medical Research, 53(11), 1069-1073.

Aly, S. M., Abd-El-Rahman, A. M., John, G., \& Mohamed, M. F. (2008). Characterization of some bacteria isolated from oreochromis niloticus and their potential use as probiotics. Aquaculture, 277(1-2), 1-6. doi:10 . 1016/j.aquaculture.2008.02.021

Angelov, A., Gotcheva, V., Kuncheva, R., \& Hristozova, T. (2006). Development of a new oat-based probiotic drink. International Journal Of Food Microbiology, 112(1), 7580. doi:10.1016/j.ijfoodmicro.2006.05.015

Anurag, P. \& Rajamohan, T. (2003). Cardioprotective effect of tender coconut water in experimental myocardial infarction. Plant Foods for Human Nutrition, 58(3), 1-12. doi:10.1023/B:QUAL.0000040363.64356. 05

Argyri, A. A., Zoumpopoulou, G., Karatzas, K.-A. G., Tsakalidou, E., Nychas, G.-J. E., Panagou, E. Z., \& Tassou, C. C. (2013). Selection of potential probiotic lactic acid bacteria from fermented olives by in vitro tests. Food Microbiology, 33(2), 282-291. doi:10.1016/j.fm.2012.10.005

Campbell-Falck, D., Thomas, T., Falck, T. M., Tutuo, N., \& Clem, K. (2000). The intravenous use of coconut water. American Journal Of Emergency Medicine, 18(1), 108-111. doi:10 . 1016 / S0735 - 6757(00) 90062-7

Chauhan, O. P., Archana, B. S., Singh, A., Raju, P. S., \& Bawa, A. S. (2014). A refreshing beverage from mature coconut water blended with lemon juice. Journal Of Food Science And Technology-Mysore, 51(11), 3355-3361. doi:10.1007/s13197-012-0825-6

Chung, H. S., Kim, Y. B., Chun, S. L., \& Ji, G. E. (1999). Screening and selection of acid and bile resistant bifidobacteria. International Journal Of Food Microbiology, 47(1-2), 2532. doi:10.1016/S0168-1605(98)00180-9

Cutting, S. M. (2011). Bacillus probiotics. Food Microbiology, 28(2, SI), 214-220. doi:10 . 1016/j.fm.2010.03.007

Demirci, A., Pometto, A. L., \& Johnson, K. E. (1993). Lactic acid production in a mixedculture biofilm reactor. Applied and Environmental Microbiology, 59(1), 203-207.
Retrieved from https://www.ncbi.nlm.nih. gov $/ \mathrm{m} /$ pubmed $/ 16348843 /$

Dharmasena, M. P. (2012). Assessment of viability of probiotic bacteria in non dairy food matrices under refrigeration storage (Doctoral dissertation, Clemson University).

Duc, L. H., Hong, H. A., Barbosa, T. M., Henriques, A. O., \& Cutting, S. M. (2004). Characterization of bacillus probiotics available for human use. Applied And Environmental Microbiology, 70(4), 21612171. doi:10.1128/AEM .70.4.2161-2171. 2004

FAO / WHO. (2001). Health and nutritional properties of probiotics in food including powder milk with live lactic acid bacteria. Cordoba, Argentina: FAO Food and Nutrition Paper, 14 October.

Gilliland, S. E., Staley, T. E., \& Bush, L. J. (1984). Importance of bile tolerance of lactobacillus acidophilus used as a dietary adjunct1. Journal of Dairy Science, 67(12), 3045-3051. doi:10.3168/jds.S0022$0302(84) 81670-7$

Hawrelak, J. (2003). Probiotics: choosing the right one for your needs. Journal of the Australian Traditional - Medicine Society, 9(2), 67-75. Retrieved from https: / / www . researchgate . net / publication / 266449396_Probiotics_Choosing_The_ Right_One_For_Your_Needs

Hyronimus, B., Le Marrec, C., Sassi, A. H., \& Deschamps, A. (2000). Acid and bile tolerance of spore-forming lactic acid bacteria. International Journal Of Food Microbiology, 61(2-3), 193-197. doi:10.1016/S01681605(00)00366-4

Jackson, J. C., Gordon, A., Wizzard, G., McCook, K., \& Rolle, R. (2004). Changes in chemical composition of coconut (cocos nucifera) water during maturation of the fruit. Journal Of The Science Of Food And Agriculture, 84 (9), 1049-1052. doi:10. 1002/jsfa. 1783

Jensen, H., Grimmer, S., Naterstad, K., \& Axelsson, L. (2012). In vitro testing of commercial and potential probiotic lactic acid bacteria. International Journal Of Food Microbiology, 153(1-2), 216-222. doi:10.1016/j. ijfoodmicro.2011.11.020 
Kalman, D. S., Feldman, S., Krieger, D. R., \& Bloomer, R. J. (2012). Comparison of coconut water and a carbohydrate-electrolyte sport drink on measures of hydration and physical performance in exercise-trained men. Journal Of The International Society Of Sports Nutrition, 9. doi:10.1186/15502783-9-1

Kandler, O. \& Weiss, N. (1986). Bergey's manual of systematic bacteriology. In P. H. A. Sneath, N. S. Mair, M. E. Sharpe, and J. G. Holt (Ed.), (Chap. Genus LactoBacillus beijerinck 1901, 212AL). Baltimore: Williams \& Wilkin.

Kodali, V. P. \& Sen, R. (2008). Antioxidant and free radical scavenging activities of an exopolysaccharide from a probiotic bacterium. Biotechnology Journal, 3(2), 245251. doi:10.1002/biot.200700208

Kuswardani, I., Kusumawati, N., Srianta, I., \& Sabrina, M. I. (2011). Survival of 1. bulgaricus and s. thermophilus in coconut water based medium during frozen storage. In The 3rd International Conference of Indonesian Society for Lactic Acid Bacteria (3rd IC-ISLAB): Better Life with Lactic Acid Bacteria: Exploring Novel Functions of Lactic Acid Bacteria, held at Yogyakarta, Indonesia, 21-22 January (2-10). Yogyakarta: ISLAB.

Lee, P.-R., Boo, C. X., \& Liu, S.-Q. (2013). Fermentation of coconut water by probiotic strains lactobacillus acidophilus 110 and lactobacillus casei 126. Annals Of $\mathrm{Mi}$ crobiology, 63(4), 1441-1450. doi:10.1007/ s13213-013-0607-z

Lorca, G. L. \& de Valdez, G. F. (2001). Acid tolerance mediated by membrane atpases in lactobacillus acidophilus. Biotechnology Letters, 23(10), 777-780. doi:10.1023/A : 1010346131918

Miller, G. L. (1959). Use of dinitrosalicylic acid reagent for determination of reducing sugar. Analytical Chemistry, 31(3), 426428. doi:10.1021/ac60147a030

Payot, T., Chemaly, Z., \& Fick, M. (1999). Lactic acid production by bacillus coagulans kinetic studies and optimization of culture medium for batch and continuous fermentations. Enzyme And Microbial Technol- ogy, 24(3-4), 191-199. doi:10.1016/S01410229(98)00098-2

Penna, A. L. B., Rao-Gurram, S., \& BarbosaCanovas, G. V. (2007). Effect of milk treatment on acidification, physicochemical characteristics, and probiotic cell counts in low fat yogurt. Milchwissenschaft-Milk Science International, 62(1), 48-52.

Pennacchia, C., Ercolini, D., Blaiotta, G., Pepe, O., Mauriello, G., \& Villani, F. (2004). Selection of lactobacillus strains from fermented sausages for their potential use as probiotics. Meat Science, 67(2), 309-317. doi:10.1016/j.meatsci.2003.11.003

Prado, F. C., Lindner, J. D. D., Inaba, J., Thomaz-Soccol, V., Bray, S. K., \& Soccol, C. R. (2015). Development and evaluation of a fermented coconut water beverage with potential health benefits. Journal Of Functional Foods, 12, 489-497. doi:10.1016/j.jff. 2014.12.020

Prasad, J., Gill, H., Smart, J., \& Gopal, P. K. (1998). Selection and characterisation of lactobacillus and bifidobacterium strains for use as probiotics. International Dairy Journal, 8(12), 993-1002. doi:10 . 1016/ S0958-6946(99)00024-2

Pummer, S., Heil, P., Maleck, W., \& Petroianu, G. (2001). Influence of coconut water on hemostasis. American Journal Of Emergency Medicine, 19(4), 287-289. doi:10 . 1053/ajem.2001.24477

Ranadheera, R. D. C. S., Baines, S. K., \& Adams, M. C. (2010). Importance of food in probiotic efficacy. Food Research International, 43(1), 1-7. doi:10.1016/j.foodres.2009.09. 009

Ranganna, S. (1986). Handbook of analysis and quality control for fruit and vegetable products. 7New Delhi: Tata McGraw Hill Publishing Co. Ltd.0.

Saat, M., Singh, R., Sirisinghe, R. G., \& Nawawi, M. (2002). Rehydration after exercise with fresh young coconut water, carbohydrateelectrolyte beverage and plain water. Journal Of Physiological Anthropology And Applied Human Science, 21(2), 93-104. doi:10.2114/.jpa.21.93

Sanders, M. E. (1999). Probiotics. Food Technology, 53(11), 67-77. 
$110 \mid$ Gangwar et al.

Yong, J. W. H., Ge, L., Ng, Y. F., \& Tan, S. N.

(2009). The chemical composition and biological properties of coconut (cocos nucifera l.) water. Molecules, $14(12), 5144$ 5164. doi:10.3390/molecules14125144 